\title{
Effect of Empathic Tones on Spelling Ability among Native Arab Children
}

Raphiq Ibrahim ${ }^{1 *}$ and Samih Badarny ${ }^{2}$

${ }^{1}$ The Edmond J. Safra Brain Research Center and the Learning Disabilities Department, University of Haifa, Haifa, Israel

raphiq@psy.haifa.ac.il

${ }^{2}$ Department of Neurology, Carmel Medical Center and Faculty of Medicine, Israel Institute of Technology,

\section{ABSTRACT} Haifa, Israel

Little research has been conducted on the development of spelling in general and in the Arabic language in particular. In this research, we intend to examine the effect of empathic tones in words on the accuracy of spelling.

The study included 162 elementary school children. They were asked to spell concrete nouns, including frequently and less frequently used words, from literary and spoken Arabic containing both empathic and non-empathic tones.

Significant effect of empathic tones on spelling accuracy was found. This manifested itself in a better spelling performance of words without empathic tones than in words with empathic tones. The research results reinforce a specific characteristic of Arabic orthography and emphasize the need for appropriate intervention to improve the spelling abilities of children.

\section{Indexing terms/Keywords}

empathic tone; spelling; phonology; Arabic; articulation.

\section{Academic Discipline And Sub-Disciplines}

Linguistics, Psychology; Education.

\section{Council for Innovative Research}

Peer Review Research Publishing System

\section{Journal: Journal of Advances in Linguistics}

Vol.6, No 1

editor@cirjal.com

jalleditoronline@gmail.com, www.cirjall.com 


\section{INTRODUCTION}

Handwriting develops in parallel to reading development. Spelling, which is the way the writer represents spoken words in writing, is an accepted measure of reading performance. Various studies have focused on different aspects of the development of reading among normal readers and readers with reading disabilities (poor readers). Yet the development of spelling in the Arabic language has received less scholarly attention, as exemplified by the fewer research studies conducted on it compared to studies in other languages (such as Hebrew and English) (Abu-Rabia \& Taha, 2004, 2006 Azzam,1993). The study conducted by Abu Rabia and Taha (2006), suggests that phonology accounts for only fifty percent of writing errors in the Arabic language. The study also concludes that phonological writing errors are the most dominant among Arab children from first grade through ninth grade.

It is worth noting that despite the high percentage of phonological writing errors found in the aforementioned study, we cannot draw conclusions regarding poor phonological ability among native Arab speakers. The study of Eviatar and Ibrahim 2000, illustrates this point by showing that the level of phonological awareness of native Arab children was similar to that of Russian speakers and higher than that of Hebrew speakers (Eviatar \& Ibrahim, 2000).

These findings are consistent with the complexity of the Arabic language; such complexity contributes to a possible difference in the relative weight of the visual and phonological processes among Arab readers. The current study examines the impact of a specific characteristic of the orthographic system in Arabic - the existence and absence of empathic tones in words - on the accuracy of spelling.

\section{Arabic Language and Spelling}

The Arabic alphabet includes twenty-eight letters representing thirty-four tones (Elbehri, Everatt, Reid \& Manni, 2006). Three letters are regarded as long vowels and the others are consonants. The shapes of the majority of Arabic letters change according to their position in the word. Twenty-two letters have different shapes of writing according to their position in the word: at the start, middle and end of the word. There are rules for writing these letters in their different shapes and rules regarding the way these letters are connected to each other ( $2, \varepsilon, \varepsilon, \varepsilon$ ) (Abu Rabia, Share \& Mansour, 2003). In addition, many letters are similar in their basic shapes, but different in the number of dots (one, two three) and their position (above, in and below the letter) (ب- ن- ن - ن).

Azzam (1993), indicates that the main factor of reading difficulties is that children must remember three or four shapes for each letter according to their position in the word and must develop the ability to distinguish between letters based on simple differences of separate features.

With regard to spelling, various systems of written language have different characteristics and spelling rules. The Arabic language as a unique system of language includes a large number of spelling and pronunciation rules. In order to have a good command of the processes of spelling, the reader must use the spelling rules skillfully (Abu Rabia \& Taha, 2006). In this context, few studies have been conducted to analyze writing errors among normal readers and readers with reading difficulties. Azzam (1993) examined writing errors among children studying Arabic from the age of 6 to the age of 11 . The writing errors made by the children were analyzed and classified into different categories including the linguistic and orthographic characteristics of the Arabic writing system. The results indicate that the writing errors expected among Arab childrenat elementary grades, show that children have difficulty in using the Arabic writing system. The writing errors focus on rules related to the association and omission of letters. Abu Rabia \&Taha $(2004,2006)$, conducted an analysis of spelling errors among fifth- grade native Arabicspeaking children, both dyslectic and normal.; Seven categories of common types of spelling errors were found in the Arabic orthography. These categories are: phonetic errors, semi phonetic errors, dysphonetic errors, visual letter confusion errors, irregular spelling errors, word omission and functional word omission. The first part of these categories is directly attributed to phonological processing; the second part is influenced by lexical processes and the command of spelling rules in the Arabic orthography; the third part of these errors are characterized by functional word omission.

In Arabic, some of the consonants are pharyngealized; this is a small group of consonants that is characterized by a feature called emphatic consonant. This feature distinguishes these consonants from others (Rabin, 1972). Emphatic phonemes cause a coarticulation effect by affecting adjacent phonemes, especially vowels. The emphatic consonants induce a considerable backing gesture (i.e., moving the tongue considerably back during articulation) in neighboring segments, primarily adjacent vowels. This effect may spread over entire syllables and beyond syllable boundaries (ElImam, 2001). In Arabic, the word صوط صو , for example, is pronounced as is not easy to determine the extent of the coarticulation effect of the emphatic and pharyngeal phonemes on their neighboring consonants and vowels. The spoken Arabic alphabet letters that carry the Arabic emphatic phonemes /D/, /S/, /T/, and /Z/ are Dhaad, Saad, T_aa, and Dhaa, respectively. In addition, the non-emphatic counterparts of these emphatic Arabic tones - /d/, /s/, /t/, and /TH/ - have the following spoken Arabic alphabet letter carriers: Daal, Seen, Taa, and Thaa, respectively. These are pronounced as: /d a: I/, /s a: n/, /t a:/, and /TH a: I/, respectively (Table 1). 
Table 1: Arabic empathic tones and their non-emphatic counterparts

\begin{tabular}{|c|c|c|c|}
\hline $\begin{array}{c}\text { Arabic } \\
\text { Alphabet } \\
\text { Letter }\end{array}$ & $\begin{array}{c}\text { Classical } \\
\text { Arabic Symbol }\end{array}$ & $\begin{array}{c}\text { IPA } \\
\text { Symbol }\end{array}$ & Non-empathic Counterparts \\
\hline $\begin{array}{l}\text { D } \\
\text { D }\end{array}$ & Dhaad & $\mathrm{s}^{\uparrow}$ & $\begin{array}{c}\omega \\
\text { /d/ Daal }\end{array}$ \\
\hline S & Saad & $d^{\varsigma}$ & Voiced: /z/ (Zain); Unvoiced: /s/ (Seen) \\
\hline $\begin{array}{l}\mathrm{b} \\
\mathrm{T}\end{array}$ & T_aa & $t^{\varsigma}$ & $\begin{array}{c}ت \\
\text { Voiced: /d/ (Daal); Unvoiced: /t/ (Taa) }\end{array}$ \\
\hline $\begin{array}{l} \\
\text { Z }\end{array}$ & Dhaa & $\begin{array}{l}z^{\varsigma} \\
\text { or } \\
\text { дৎ }\end{array}$ & $\begin{array}{c}\dot{j} \\
/ \mathrm{TH} /(\text { Thaal) }\end{array}$ \\
\hline
\end{tabular}

We assume that these specific consonants require the child to invest more effort in spelling compared with other consonants. In addition to their primary place of articulation, these consonants have one or two different manners of articulation. This is manifested by a secondary articulation of consonants that leads to empathic tones (Laufer, 1987). Empathicness is a feature that distinguishes between phonemes: there are pairs of different words whose only difference is the feature of empathicness in one of the consonants. This leads to an entirely different meaning of words (تين, طين/ سار, ) صار). Note that, apart from the main place of articulation, two additional manners of articulation exist. The tone is accompanied by muscular shrinking and zooming to the back of the tongue: e.g. سفر [safar] ('journey')/ صفر [sarar] (name of the second month in the Muslim calendar); نين [tiùn] ('figs')/طين [tiùn] ('clay'); درب [darb] ('alley')/ضرب [d³Arb] ('attack'). In Semitic languages, there are two types of empathicness: pharyngealization ${ }^{1}$ and velarization ${ }^{2}$. Pharyngealization denotes the addition of a constriction in the pharynx during the production of a given sound. As velarization often goes hand- inhand with pharyngealization, or no distinction is made between them by native speakers of the language in which it occurs. The International Phonetic Alphabet (IPA) diacritic is the same for both. When a clear difference should be made, the IPA uses a raised $\grave{A}$ for pharyngealization (e.g. [ $\left.\mathrm{s}^{3}\right]$ ), and a superscript $\ddot{A}$ (e.g. [nì]) for velarized sounds. In addition, there are assimilations and differentiations within a word and within a syllable, that influence the whole syllable and even the adjacent syllables (e.g. خ مط - mat'́bax ) (Al-Ani, 1970).

\section{Models of Spelling Development}

Many scholars have studied the affinity between the development of reading and decoding skills and the development of spelling. Today, it is known that there is a link between the acquisition of reading skills and possessing a command of the processes of spelling (Curtin, Manis, \& Seidenberg, 2001; Ellis, 1993). Frith (1985), argues that the speller moves from an alphabetic spelling stage where she relies on mapping processes of phonemes to graphemes; and from an orthographic spelling stage where the speller can spell odd words that are not written through the mapping of the phonemes to graphemes. In the orthographic stage, there is a need for developing a lexical channel that enables extracting these specific orthographic templates to phonological outputs, namely the pronounced words (Lennox \& Siegel, 1998). Many researchers suggest that it is the development of this lexical channel that enables the command for the specific spelling of writing templates, especially odd words, which in itself is a result of the normal acquisition of reading skills (Snowling, 1987). According to researchers, this normal acquisition of reading constitutes a factor in the normal development of the orthographic lexicon that enables command of spelling processes. Therefore, we can understand the link between reading difficulties and spelling difficulties (Ellis, 1993). Consistent with the above discussion, the orthographic lexicon that enables the normal processes of spelling must include the specific knowledge of the different writing templates. Also it must include the knowledge of the specific spelling rules for the orthographic system in which the spelling process takes place.

\section{THE CURRENT STUDY}

The interaction between the development of reading and the development of spelling ability in the Arabic language has not been researched sufficiently. Therefore, the current study focuses on the existence of the empathic tone in words. The basic premise is that the accuracy in spelling words will be higher in words without empathic tone than in words with empathic tone.

${ }^{1}$ Pharyngealization is a secondary articulation of consonants or vowels by which the pharynx or epiglottis is constricted during the articulation of the sound

${ }^{2}$ Velarization is a secondary articulation of consonants by which the back of the tongue is raised toward the velum during the articulation of the consonant. 


\section{Method}

\section{Participants}

162 native Arabic-speaking children participated in the current study: 67 boys and 95 girls, studying at regular schools in Israel. The children were chosen from three age groups at an Arab elementary school in the north of Israel:: 40 children at the beginning of $2^{\text {nd }}$ grade; 60 children at the end of $2^{\text {nd }}$ grade and 62 children at the end of $4^{\text {th }}$ grade. Children with learning disabilities (based on professional reports of the school staff) were excluded.

\section{Tools and Stimuli}

For the spelling test 54 words were dictated. The words were categorized into two groups: a) Literary (or Modern Standard Arabic-MSA), b) Words shared by both the literary and the spoken language. In both groups, frequently and non-frequently words used half of them with empathic tone and the other half without empathic tone (Asadi, Shany, Ben-Semon \& Ibrahim, 2012).

\section{Procedure}

Each participant was asked to write each word he/she heard from the total of 54 words included in the test at his/her own pace. The test was administered individually in a quiet school room. At the end of this task, the child's familiarity with the words spelled in the dictation test was evaluated using a test of definitions. Each test lasted 20 minutes for each participant.

\section{Results}

In this study, we examined whether a difference exists between spelling words with empathic tones compared to those without empathic tones in each group. For this purpose, percentages and standard deviations were calculated for the percentage of the correctly spelled words with empathic tone compared to those without empathic tone in each group of words (See Table 2).

In order to examine this question, two measures were calculated and two grades were given: the percentage of the correctly written words in the test and the percentage of the correctly written letters in the test.

Table 2: Means and Standard Deviations (SD) for The Percentages of the correctly spelled words With empathic tone and Without empathic tone in each group of words

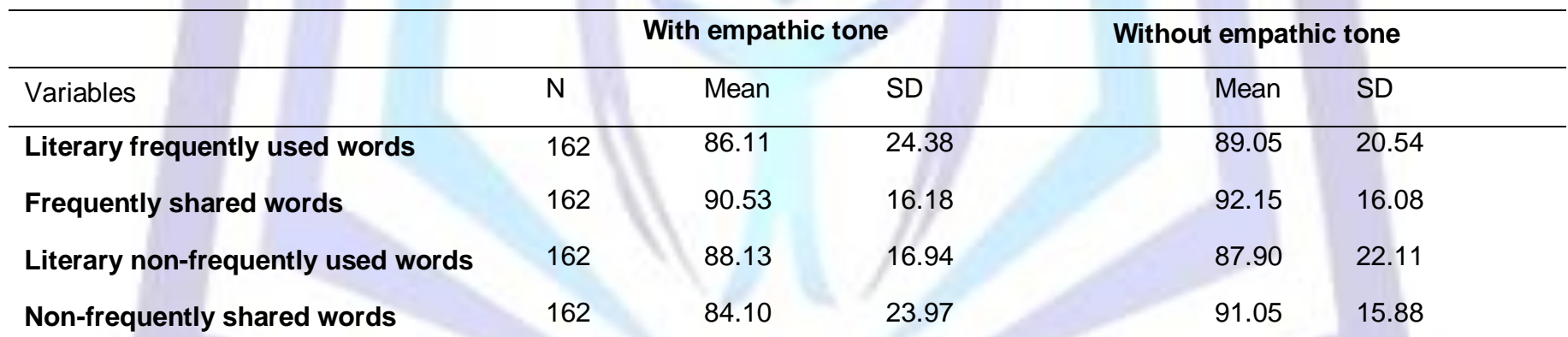

Two series of $T$ analyses for dependent variables were conducted. The first series examined whether there was a difference in the number of the correctly spelled words out of the total 54 words in the spelling task. The t-analysis indicated that from the various comparisons, there is significant difference for the comparison between literary frequently used words with empathic tone and literary frequently used words without empathic tone $t_{(161)}=3.08, p<0.01$. Also, a significant difference was found between frequently shared words with empathic tone and those without empathic tone $\mathrm{t}_{(161)}=5.85, \mathrm{p}<0.001 \mathrm{H}$. owever, no significant difference was found between frequently shared words with empathic tone and those without empathic words $\mathrm{t}_{(161)}=1.79$, n.s, or between non-frequently used literary words with empathic tone and those without empathic tone $\mathrm{t}_{(161)}=0.19$, n.s.

A second series of T-analyses was conducted for the purpose of examining the difference in the percentage of the correctly spelled letters (221 letters in totoal). T-analyses indicated significant differences in the correctly spelled letters in frequently used literary words with empathic tone and those without empathic tone $t_{(161)}=3.84, p<0.001$. Also, a significant difference was found between the percentage of the correctly spelled letters in non-frequent shared words with empathic tone and those without empathic tone $\mathrm{t}_{(161)}=4.85, \mathrm{p}<0.001$.

However, no significant differences were found between frequently shared words with and without empathic tones $\mathrm{t}_{(161)}=1.18$, n.s nor in the between non-frequently used literary words with and without empathic tones $t_{(161)}=0.38$, n.s. Table 3 displays the means and standard deviations for the percentages of the correctly spelled letters in each group. 
Table 3: Means and Standard Deviations (SD) for The Percentages of the correctly spelled letters With empathic tone and Without empathic tone in each group of words

\begin{tabular}{llccc}
\hline & & \multicolumn{2}{l}{ With empathic tone } & \multicolumn{2}{c}{ Without empathic tone } \\
\hline Variables & $\mathrm{N}$ & Mean & SD & Mean \\
\hline Literary frequently used words & 162 & 96.02 & 0.08 & 97.16 \\
Frequently shared words & 162 & 97.18 & 0.05 & 97.55 \\
Literary non-frequently used words & 162 & 97.20 & 0.05 & 97.07 \\
Non-frequently shared words & 162 & 95.64 & 0.07 & 9.06 \\
\end{tabular}

\section{DISCUSSION}

The current study examines the impact of empathic tones (consonants with empathicness), an important feature in the Arabic language, on the performance of spelling tasks for both literary word and words shared by spoken Arabic and literary Arabic (shared words).

The results of the study indicate that there is a difference between spelling words in literary Arabic and shared words with empathic tone and those without empathic tone. The study's results indicate that there is an advantage for spelling words without empathic tone over words with empathic tone. This advantage is maintained at all grade levels. This finding is consistent with the literature that explains the feature that characterizes these tones (Laufer, 1987). Apart from the primary place of articulation, there are two manners of articulation. The feature of empathicness distinguishes between phonemes: there are pairs of words where the only difference between them is the feature of empathicness in one of the consonants which leads to a different in the meaning of the words. In addition, the feature of empathicness of the empathic tones influences the way these tones are pronounced and makes it difficult to identify the pronounced consonant for the sake of spelling. The feature of empathicness causes one consonant to influence the other, that is, there is regressive or progressive assimilation, as a consonant with empathicness in the word influences the pronunciation of other consonants without empathicness, something that influences the performance on the spelling task.

Spelling error can be attributed to the speller's inability to distinguish between the tones and the different phonemes he hears even though these tones are pronounced correctly. In such situations, the speller cannot match the tone with its writing shape. This occurs as the speller cannot remember or internalize the shape due to insufficient practice or experience.

From the various comparisons regarding spelling words with and without empathic tone in each group (frequently- used literary and non-frequently-used literary; frequently used shared and non-frequently used shared), the results indicate a significant difference in the groups of frequently used literary words with and without empathic tone as well as in the group of non-frequently used shared words with and without empathic tone.

Another source of difficulty is likely found in coarticulation, that is, the effect that a surrounding phoneme can have on the pronunciation of a target sound. For example, a non-emphatic sound may take on an emphatic quality due to the presence of a neighboring emphatic consonant. Thus, although there are four emphatic phonemes in Arabic, other non-emphatic phonemes may be pharyngealized due to the existence of a neighboring emphatic tone. Spelling errors may be caused by this factor. In studies of several Arabic dialects, the effect of pharyngealization has been found to spread beyond the immediate neighboring segment to other segments in the word. The spread can be in different directions (left and right) and in different domains such as syllable and word (Watson, 1999).

\section{CONCLUSIONS}

This study tried to examine the effect of empathic tones of words on the accuracy of spelling. A cross-grade test was conducted using four emphatic consonants and their non-emphatic counterparts in Literary or Modern Standard Arabic (MSA). The investigation revealed discrepancies between empathic and non-emphatic phonemes. Significant effect of the existence of empathic tones on spelling accuracy was found. This manifested itself in a better spelling performance of words without empathic tones than in words with empathic tones. The research results reinforce specific characteristic of Arabic orthography and emphasize the need for interventions to improve the spelling abilities among children. Furthermore, as this finding is the first of its kind in the Arabic language, the study noted several significant directions for future research.

The research findings indicate a necessity for taking into consideration morphological complexity versus simple morphology when examining the process of spelling words in Arabic. As is already known, the Arabic language is rich in words that are morphologically complex. The study of morphology has not been comprehensively researched. Thus, different systematic ways for studying mainly spelling tasks should be investigated (Abu Rabia \& Awwad, 2004).

Concerning the practical conclusions, the study's findings would indicate a need for systematic exposure to the literary language as early as kindergarten-age for the purpose of bridging the gaps in the existing knowledge between shared templates in the spoken and the literary language and those existing only in the literary language. This exposure would make it easier for children at a young age to internalize morphological and phonological rules in the two forms of the 
language; it would minimize the difference between them and help them to remember the audial pattern of the literary words. All the aforementioned facilitate the process of spelling.

Finally, related processes such as labialization ${ }^{3}$ are also found in Arabic dialects. The role of coarticulation and spreading in MSA and their effects on Arabic spelling remains to be determined.

\section{REFERENCES}

[1] Abu-Rabia, S., and Awwad, J. (2004). Morphological structures in visual word recognition: The case of Arabic. Journal of Research in Reading, 27, 321-336.

[2] Abu-Rabia, S., Share, D. \& Mansour, M. (2003).Word recognition and basic cognitive processes among readingdisable and normal readers in Arabic. Reading and Writing: An Interdisciplinary Journal, 16, 423-442.

[3] Abu-Rabia, S. \&Taha, H. ( 2004). Reading and spelling error analysis of native Arabic dyslexic readers. Reading and Writing: An Interdisciplinary Journal, 17, 651-689.

[4] Abu-Rabia, S. \& Taha H. (2006) - Phonological Errors in Arabic Spelling Across Grades 1-9. Journal of Psycholinguistic Research, V. 35,N. 2,167-188.

[5] Al-Ani, S.H. (1970). Arabic phonology: An acoustical and physiological Investigation. The Hague: Mouton.

[6] Asadi, I, Shany. M, Ben-Semon. A., \& Ibrahim, R (2014). Individual Diagnostic Tests in the Assessment of Learning Disabilities in Arabic: Tests and Manual. University of Haifa, Haifa.

[7] Azzam, R. (1993). The nature of Arabic reading and spelling errors of young children. Reading and writing: An Interdisciplinary Journal,5, 355-385.

[8] Curtin, S., Manis, F, R., \& Seidenberg, S, M., (2001). Parallels between the reading and spelling deficits of two subgroups of developmental dyslexics. Reading and Writing: An Interdisciplinary Journal, 14, 515-547.

[9] Elbeheri, G., Everatt, J., Reid, G., \& Mannai, H. (2006). Dyslexia assessment in Arabic. Journal of Research Special Educational needs, 6(3), 143-152.

[10] El-Imam, Y. A. (2001). Synthesis of Arabic from Short Sound Clusters. Computer Speech \& Language, 15(4), 355380.

[11] Ellis, A, w. (1993). Reading, writing and dyslexia: A cognitive analysis. Hove, UK: Erlbaum.

[12] Eviatar Z. \& Ibrahim R. (2000). Bilingual is as bilingual does: Meta-linguistic abilities of Arab- speaking children. Applied Psycholinguistics, 21,451-471.

[13] Frith, U. (1985). Beneath the Surface of Developmental Dyslexia. In: Patterson, K. E., Marashall, J. C., \&Coltheart, M.(Eds), Surface dyslexia. ( pp,301-330). London: Lawrence Erlbaum Associates.

[14] Laufer A. (1987), Intonation. Jerusalem, the Hebrew University of Jerusalem, the Institute ofJewish Studies, Hebrew Language Department. (Hebrew)

[15] Lennox, C., \& Siegel, L. S. (1998). Phonological and orthographic processes in good and poor readers. In: C. Hulme \& R.M. Joshi: ( Eds.), Reading and spelling: Development and disorders .(pp, 395-404). London: Lawrence Erlbaum Association, Publishers.

[16] Rabin,Ch.M. (1972). Semitic languages. Encyclopedia Judaica (Jerusalem: Keter) , 14, 1149-1157.

[17] Snowling, M. (1987). Dyslexia: A cognitive developmental perspective. Cambridge: Gomeh Scientific Publications.

[18] Watson, J.C.E. (1999). The directionality of emphasis spread in Arabic. Linguistic Inquiry, 30, 289-300.

\section{Author' biography}

Raphiq Ibrahim. Senior researcher at the Edmond J. Safra Brain Research Center and the Department of Learning Disabilities at University of Haifa, where he is an Associate Professor of Neuropsychology. His research focuses on the cognitive processing of oral and written language. He is investigating brain regions involved in monolinguals and language selection processes in bilinguals and focuses on the hemispheric specialization of higher cognitive function

Samih Badarny. Head of Parkinson and other movement disorders services, Department of Neurology, Carmel Medical Center and Faculty of Medicine, Israel Institute of Technology, where he is a senior lecturer of Neurology.

\footnotetext{
${ }^{3}$ Labialization is a secondary articulatory feature of sounds in some languages. It involves the addition of lip rounding to the production of a sound, and is represented in the IPA by means of a raised $w(w)$. This phenomenon is found in a number of languages in Africa (e.g. Amharic in Ethiopia and Arabic in Morocco). In Arabic, labialization is a common feature in many consonants in the Moroccan dialect (particularly in Marrakeshi): e.g. [gw«lt], 'I said'. 